\title{
MODELLING CONVEYOR BELT PASSAGE WITH A DRIVING DRUM USING FINITE ELEMENT METHODS
}

\author{
Nikoleta Mikušová1, Slavomír Mill'o' \\ 1 Technical University of Kosice, Letna 9, 04200 Kosice, Slovak Republic, e-mail: nikoleta.mikusova@tuke.sk; \\ slavomir.millo@student.tuke.sk
}

Received: 2017.10.15

Accepted: 2017.11.01

Published: 2017.12.05

\begin{abstract}
Finite element methods are used in many disciplines for the development of products, typically in mechanical engineering (for example in automotive industry, biomechanics, etc.). Some modern programs of finite element methods have specific tools (electromagnetic, fluid and structural simulations). The finite elements methods allow detailed presentation of structures by bending or torsion, complete design, testing and optimization before the prototype production. The aims of this paper were model a conveyor belt passage with a driving drum. The model was created in Abaqus CAE program. The created model presented data about forces, pressures, and deformation of the conveyor belt.
\end{abstract}

Keywords: belt conveyor, belt, finite element method.

\section{INTRODUCTION}

The use of computer programs and technologies is almost an imperative in modern times [1] [2], and this is also true for solving of belt conveyor problems [3]. The use of modern technologies, or computer programs, is advantageous both from time aspect and also from an economical aspect [4]. For the creation of a computer model of a conveyor belt, it is possible to use finite element method [5]. The finite element method is a numerical method used to simulatef the course of tension, deformation and other forces acting on the object under investigation [6]. This method is used also by the program Abaqus CAE in which the movement of a conveyor belt through a drive drum was modeled. Conveyor belt is a very important part of belt conveyors. [7][8][9]. Conveyors are used in many industries due to their properties. Belt conveyors belong to the most managing types of conveyors [10]. They are engineered for sophisticated conveying of material and they can convey material with the minimal demands of energy and by this way they can reduce costs for material handling [11]. The aim of the study was to form conveyor belt to the form of a trough and ensure its graded transition through the drive drum. The basis for the model was the calculation of the forces and frictions that act on the conveyor belt and idler rollers. The size of these forces and frictions depends on the parameters, such as the length and width of the belt, number of rollers in the idler rollers, number of idler rollers and their spacing. Information and data obtained after model completion can be used by the practical implementation of the conveyor.

\section{THE FINITE ELEMENT METHOD}

The finite element method is a numerical method, used to simulate the course of deformation, heat flow, frequencies, fluid flow, and many other physical phenomena on the created physical model. The finite element method requires partitioning of the areas of the object into the final number of sub-areas or elements. Therefore, it is necessary to create a network of finite elements. For each type of elements, apart from its dimension and form, the number and position of its nodes are characteristic. Nodes of network are 
points where we look for unknown parameters of solutions - such as feeds from which pressures and tensions are calculated. Therefore, by a solution of the problem by the finite element method, it is needed to divide the continuum or the entity into the finite number of sub-areas - elements. [12] The best understanding of the finite element methods is by its practical application, which is known as finite element analysis. Finite element analysis is applied in mechanical engineering as a calculation tool for the realization of technical analysis [13]. It includes the use of technologies that divide the continuous problem into small, individual parts [14]. Finite elements analysis is a good choice for analysis of problems in complex areas (such as automobiles or pipelines), when the area changes (by reaction of the parts in solid state with movable parts), when the required accuracy varies across the area, or the solution lacks fluency. This method can be also used for modeling of conveyor belts and its properties and it helps also for the economic level of their operation, above all attention to causes which cause degradation and damage of the belt. For example, Honus et al. [5] presented an interesting application of the finite element modeling of the stress-strain states in conveyor belts. Lodewijks [15] [16] [17] dealt with possible ways of the finite element method applied to the detailed research of selected problems of conveyor belts. Mazurkiewicz [18] presented the use of finite element methods by the right material properties determination.

\section{CREATION OF THE COMPUTATIONAL MODEL}

Abaqus CAE was used to create a computational model. We focused on the adhesion and passing of the conveyor belt of the conveyor through the drum. The model consists of idler station, drum, and belt.

Parts: in the section "Part", 3 sections were created, so-called parts, which create the model of the conveyor belt. First, a roller with a radius of $70 \mathrm{~mm}$ and length of $450 \mathrm{~mm}$ was created. To simplify the calculation, the rollers were divided into 2 parts using the tool "Create Partition" (Figure 1). Subsequently, a drum with a radius of $500 \mathrm{~mm}$ and length of $1400 \mathrm{~mm}$ (Figure 2) was formed. Finally, a belt with a length $4000 \mathrm{~mm}$ and width of $1200 \mathrm{~mm}$ (Figure 3) was formed. The belt was divided into individual parts, which simplifies the calculation.

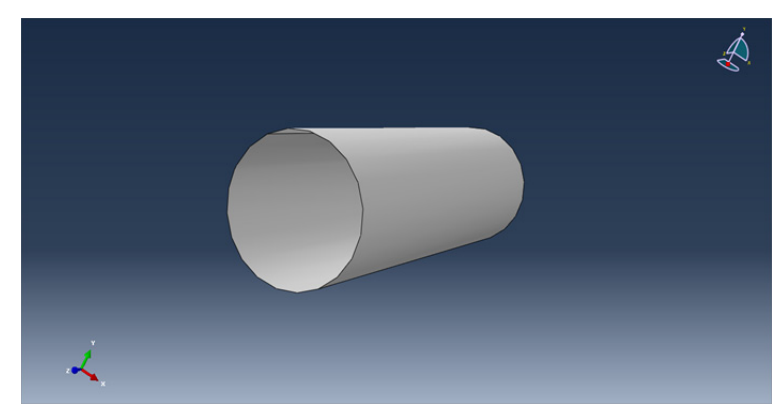

Fig. 1. Roller

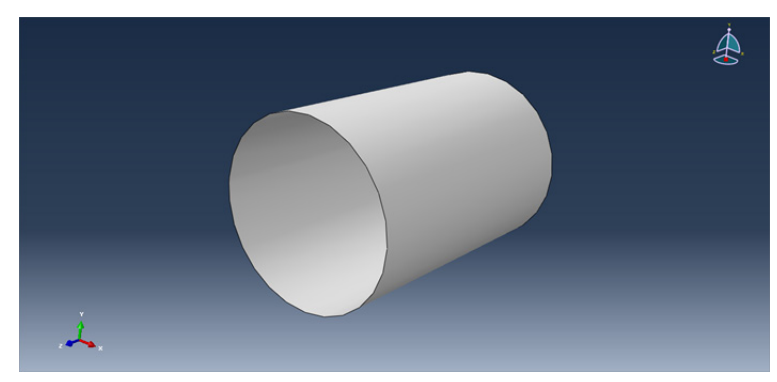

Fig. 2. Drum

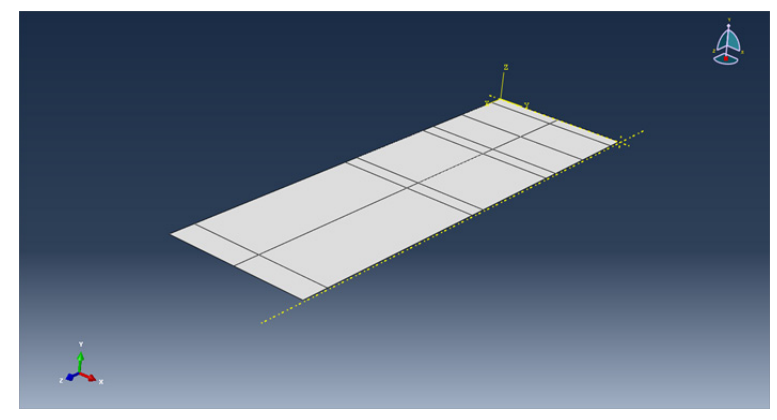

Fig. 3. Conveyor belt

Materials: the next step was to assign material properties to individual parts. For the metal parts, i.e. rollers and drum, the selected material was steel with a density of $7.85 \mathrm{E}^{-009}$, Young modulus of elasticity $204000 \mathrm{MPa}$ and Poisson`s number 0.25 [19] [20] (Figure 4). For the nonmetallic parts of the conveyor belt, a material with density $1,099 \mathrm{E}^{-009}$ (Figure 5) was selected.

Assembly: in the section "Assembly", the parts were tagged together (Figure 6). Three idler stations were distributed under the conveyor belt, the spacing was $1000 \mathrm{~mm}$. The spacing between rollers was $20 \mathrm{~mm}$. The drum was distant from the end roller station also $1000 \mathrm{~mm}$. Networking with the value $40 \mathrm{~mm}$ in this section was also defined.

Steps: the calculation was designed in two steps. The size of the first step was determined to 


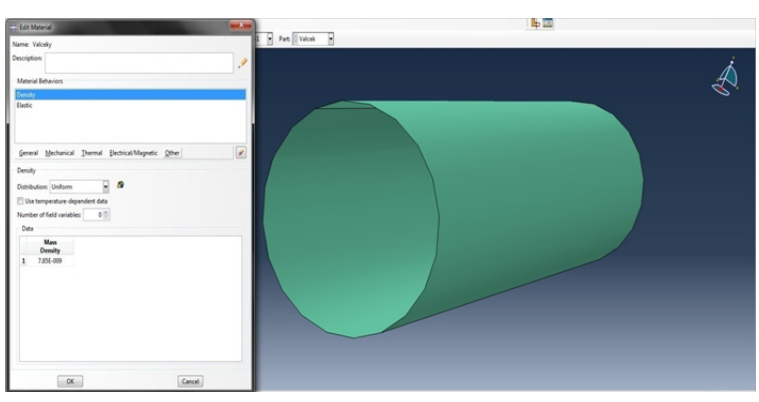

Fig. 4. Material properties of roller

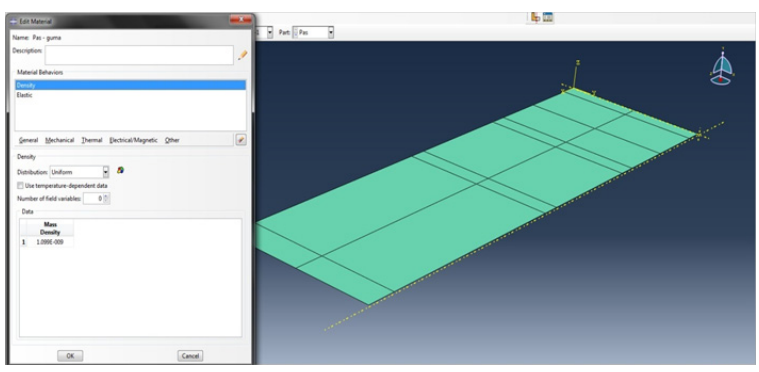

Fig. 5. Material properties of conveyor belt

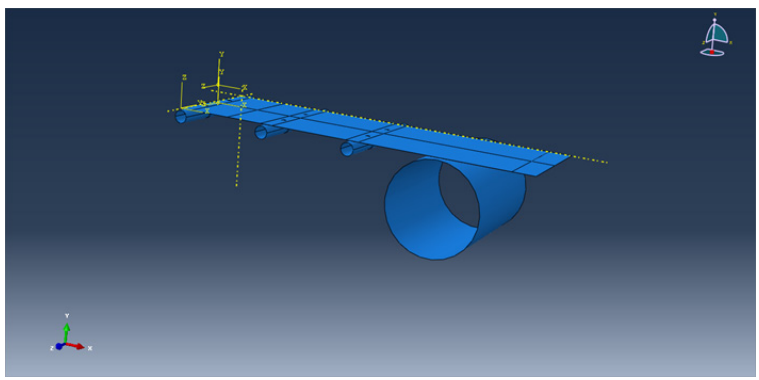

Fig. 6. Complex model of the belt conveyor

0.025 , and the size of the second step was determined to 1 .

Interactions: four interaction were determined in the section "Interaction", namely among three idler stations, drum and conveyor belt (Figure 7). Interactions were created at the point where the rollers or the drum come in contact with the conveyor belt.

Loads: tensioning the belt by gravity is specified in the section "Loads". The belt is stretched by gravity with a force of 9810 $\mathrm{kg} \cdot \mathrm{m} / \mathrm{s}^{-2}$. The belt is also stretched by the tensioning force at the point where it passes through the drum, with a force $10686.14 \mathrm{~N}$, respectively $0.05 \mathrm{MPa}$.

Boundary Conditions: with the help of "BCs" (Boundary conditions), the boundary conditions for rollers and drum were defined. The drum, as well as the rollers in the centre of the idler stations, are firmly anchored by the function "Encastre" and cannot rotate or move. On the contrary, the side rollers are rotated in the direction of the axis $\mathrm{X}$ by $30^{*}$, respectively by $0.5235 \mathrm{RAD}$.

Jobs: after the above-said conditions and requirements setting, in the section "Jobs" the calculation, and respectively the simulation are realized.

In the figures below (Figure 8 and 9), it is possible to see how the tension affected on the conveyor belt in the individual steps of the calculation. In the first step, the side rollers were lifted to the required value, and the belt was loaded with a gravitational force. In the second step, a stretching force was developed on the belt, and this realized its adhesion to the drum.

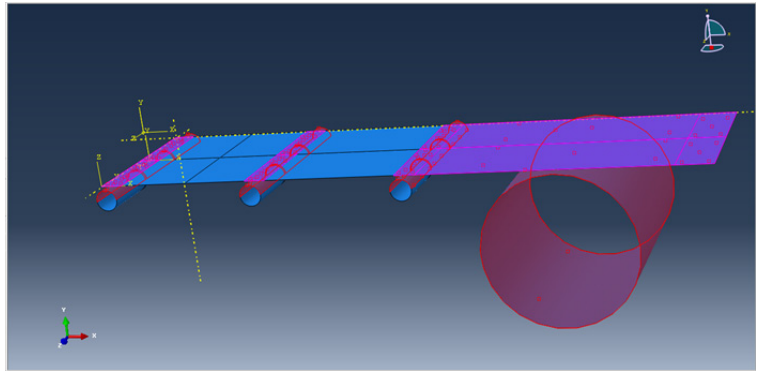

Fig. 7. Interaction among belt, rollers and drum

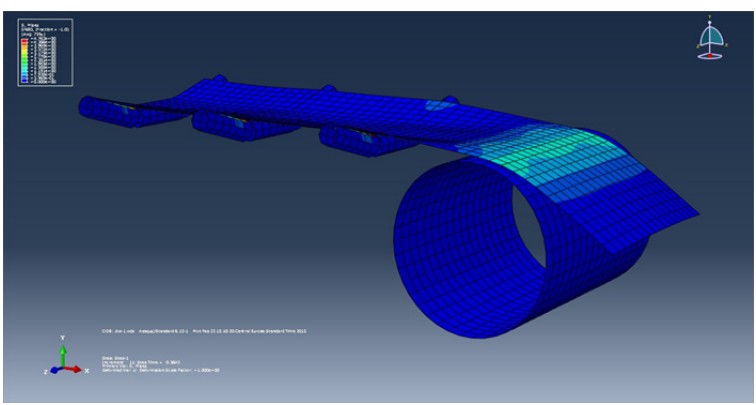

Fig. 8. Model in the middle of calculation

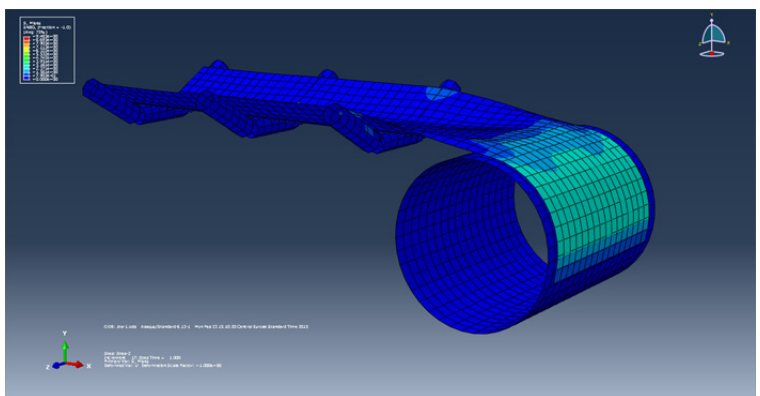

Fig. 9. Model after ending of calculation 


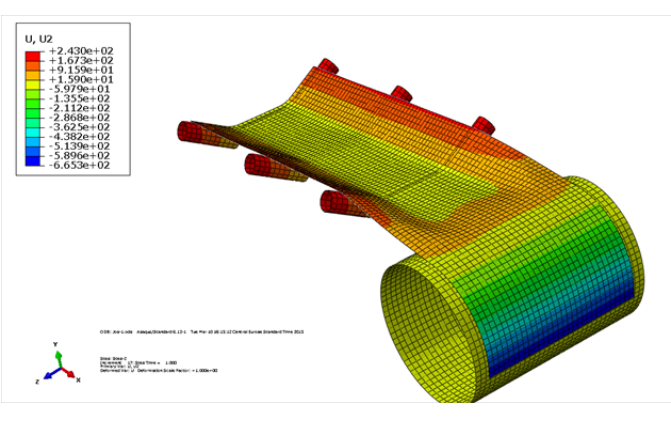

Fig. 10. Deformation forces acting to the belt

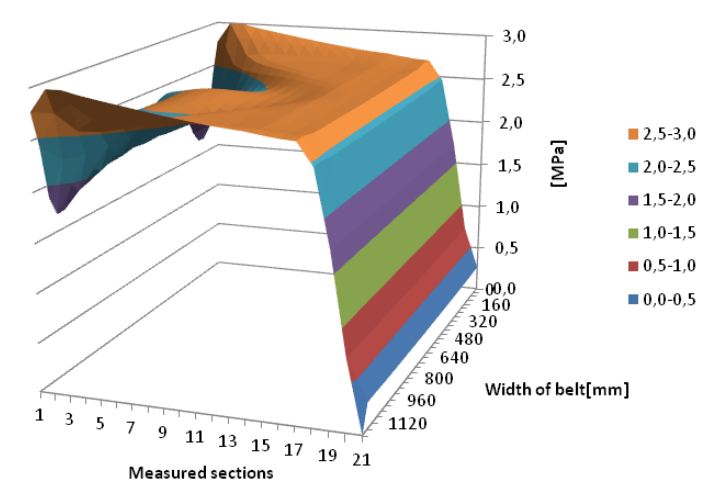

Fig. 11. Pressure on the belt by passing through the drum

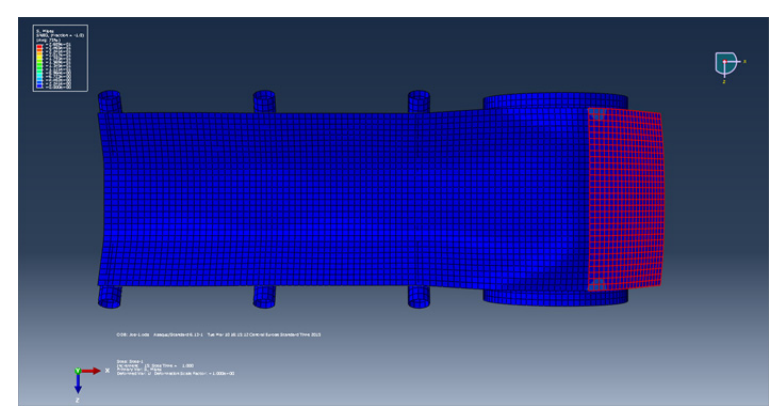

Fig. 12. Location of the pressure measurement by passing the belt through the drum

It is also possible to see, in which sections the belt was most deformed or bent (Figure 10). The largest deformation was at the edges of idler stations, where the belt bent to the trough.

In the following graph (Figure 11) it is possible to see how the pressure acted to the conveyor belt at the point, where it passed through the drum. The graph shows that the greatest pressure is at the point of conveyor belt leading to the drum. On the contrary, the smallest pressure acting on the belt is at the end of the drum.

The data were obtained from the following section of the belt (Figure 12).
Pressures on the idler stations are shown in the following graph (Figure 13). The graph shows that the greatest pressure is exerted on the idler station in front of the drum, i.e. on the idler station No. 1. The highest measured pressure was 28.2 $\mathrm{MPa}$ at the point of the rollers bending. The lowest measured pressure on this idler station, as well as on the remaining two idler stations, is on the middle roller because any forces applied to this roller. The value is $0 \mathrm{MPa}$.

Data were obtained and measured from the following section on the idler station No. 1 (Figure 14).

The pressures on the idler station No.2 and 3 were almost identical. Idler stations No. 2 and

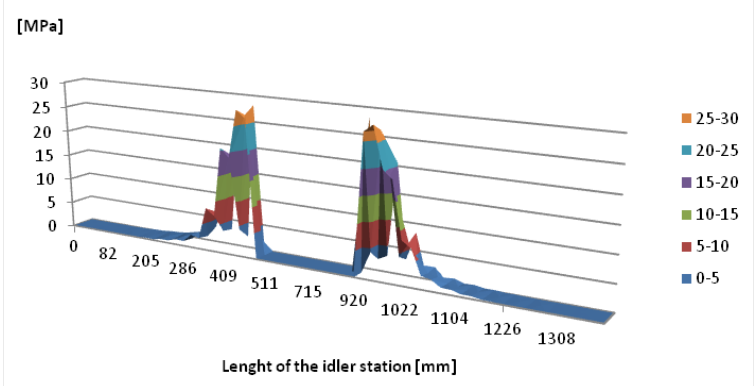

Fig. 13. Pressure on the first idler station

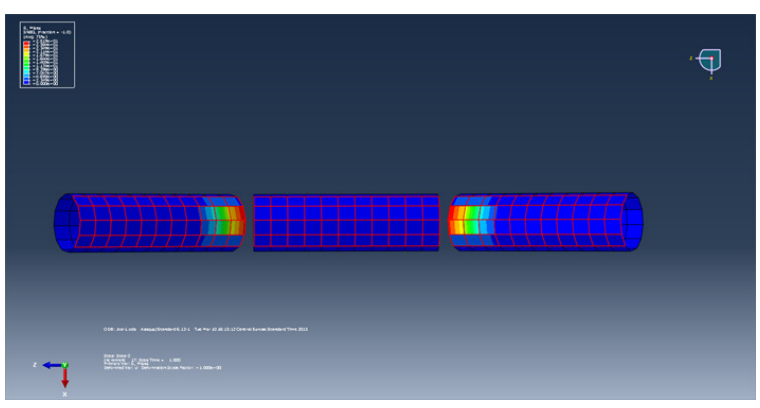

Fig. 14. Location of the pressure measurement on the idler station No. 1

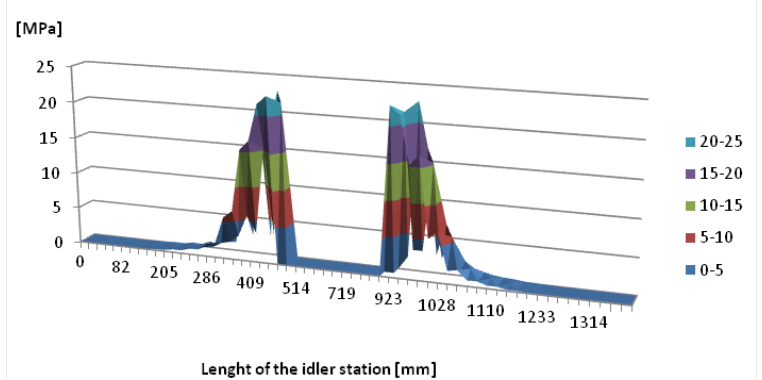

Fig. 15. Pressure on the second idler station 


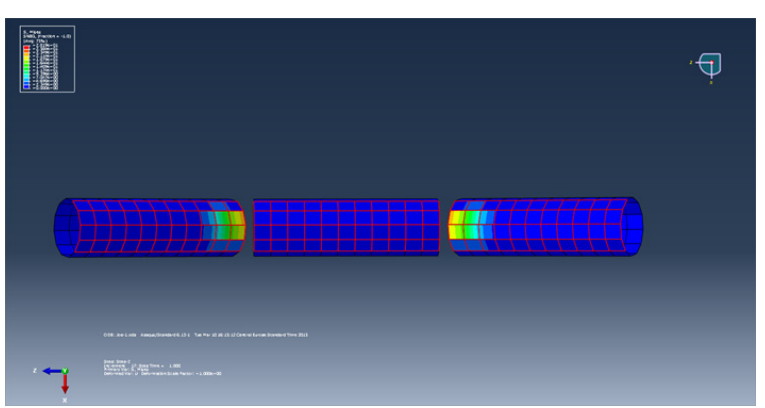

Fig. 16. Location of the pressure measurement on the idler station No. 2

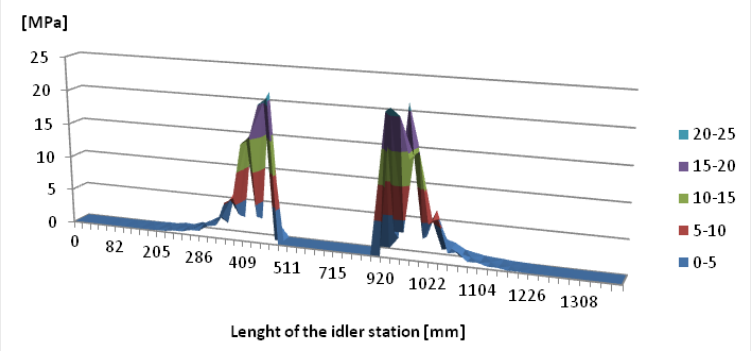

Fig. 17. Pressure on the third idler station

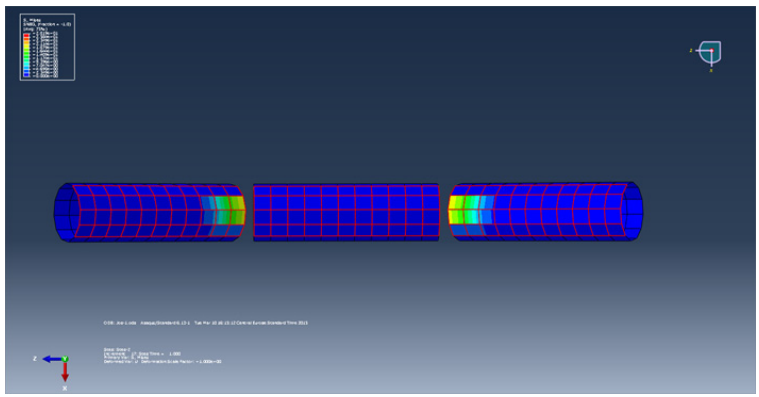

Fig. 18. Location of the pressure measurement on the idler station No. 3

No. 3 were stations which are further away from the drum. The highest measured pressure on the idler station No. 2 was $22.8 \mathrm{MPa}$, and the lowest measured pressure, $0 \mathrm{MPa}$, was again on the middle roller, without any forces (Figure 15).

The data were obtained and measured from the following section on the idler station No. 2 (Figure 16).

On the idler station No. 3 the highest measured value was $21,15 \mathrm{MPa}$. In comparison with the maximum measured values on the idler station No. 1 and No.2, the measured maximum value on the idler station No. 3 was the lowest (Figure 17). But this value is comparable to the value of the idler station No. 2. Similarly, as in the previous two cases, the lowest measured value was on the central roller, it was $0 \mathrm{MPa}$. Data were obtained and measured from the following section on the idler station No. 3 (Figure 18).

The following graph presents the deformation of the conveyor belt over the idler stations (Figure 19). The data used for the creation of these graphs were obtained and measured from the following sections of the conveyor belt. The idler station one is the station which is the closest to the drum.

The measured values on the conveyor belt at the point over the idler stations were relatively the same because the rollers were rotated in all cases at the selected $30^{\circ}$, and there was no change of material or other characteristics of the conveyor belt (Figure 20).

The measured values above the idler station No. 2 are relatively identical, the height of the belt above the idler station was again increased by $180 \mathrm{~mm}$ at a $30^{\circ}$ angle (Figure 21).

The measured values above the idler station No. 3 did not change significantly, the belt was again raised by $180 \mathrm{~mm}$ at the angle $30^{\circ}$. In this case, the values were measured only on three segments (Figure 22).

\section{CONCLUSION}

The results of this study provide unambiguous information and data about the forces acting on the conveyor belt, pressures in the belt and idler stations, i.e. tensioning force acting on the conveyor belt at the point of passage through the drum, furthermore, the pressures that arise from the rotation of rollers in the idler stations. Last but not least, these are deformation forces generated by rotation of the rollers which ensure the deformation of the conveyor belt to the $\mathrm{U}$ form, or in the form of a trough. These data were obtained from the computational model of the conveyor belt, which was modeled in the program Abaqus

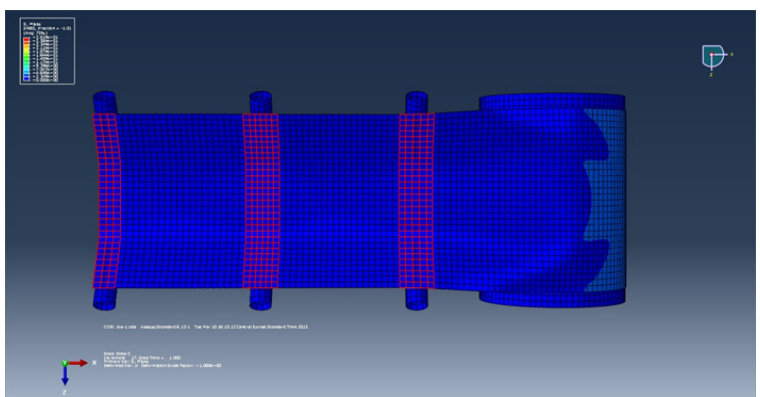

Fig. 19. Locations of measurement of the belt deformation over the idler stations 


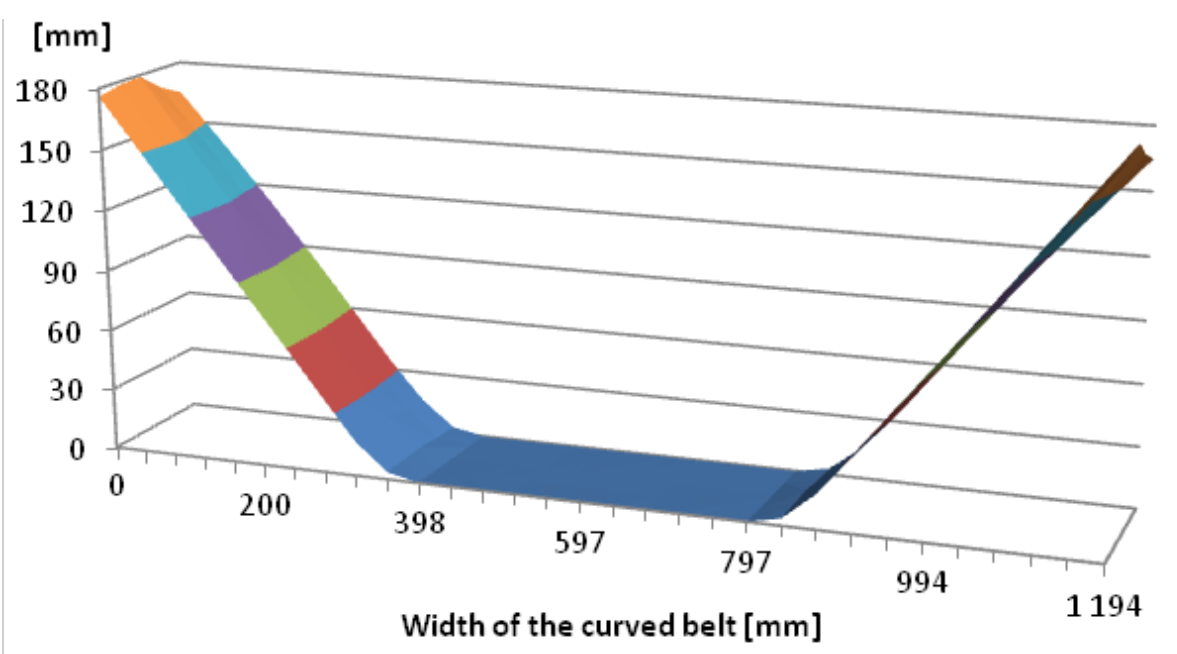

—150-180

-120-150

- $90-120$

- 60-90

- $30-60$

- $0-30$

Fig. 20. Change of belt position above the first idler station (deformation of the belt above the idler station No. 1)

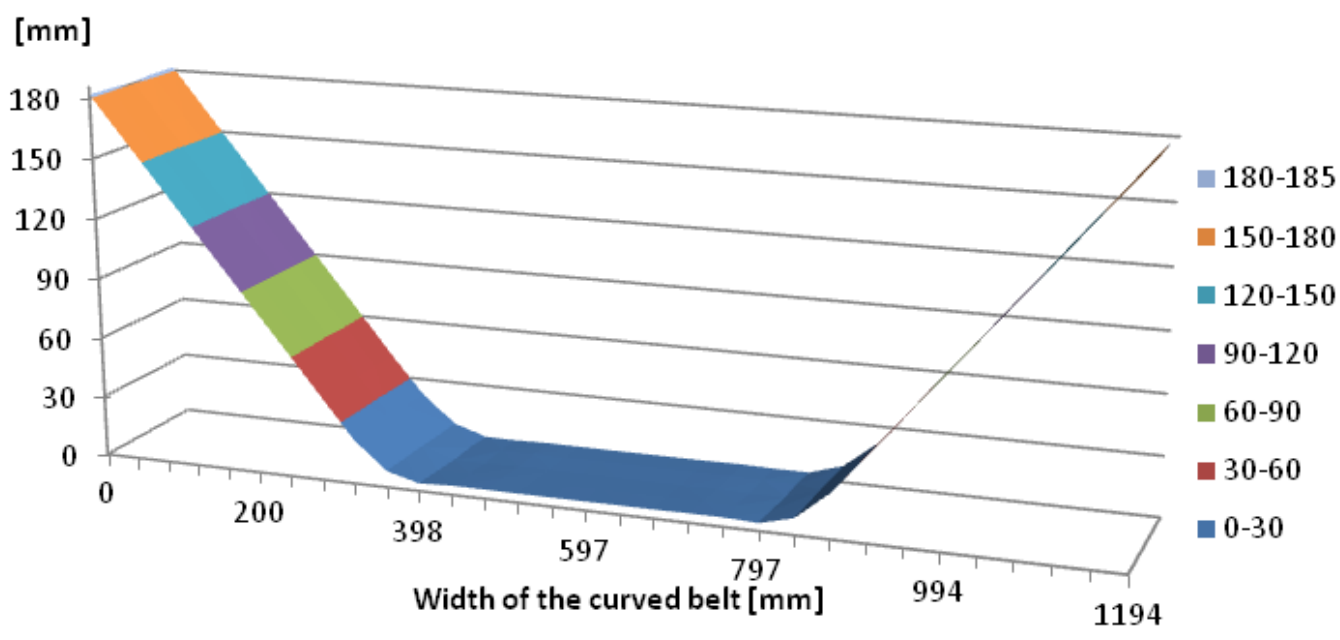

Fig. 21. Change of belt position above the second idler station (deformation of the belt above the idler station No. 2)

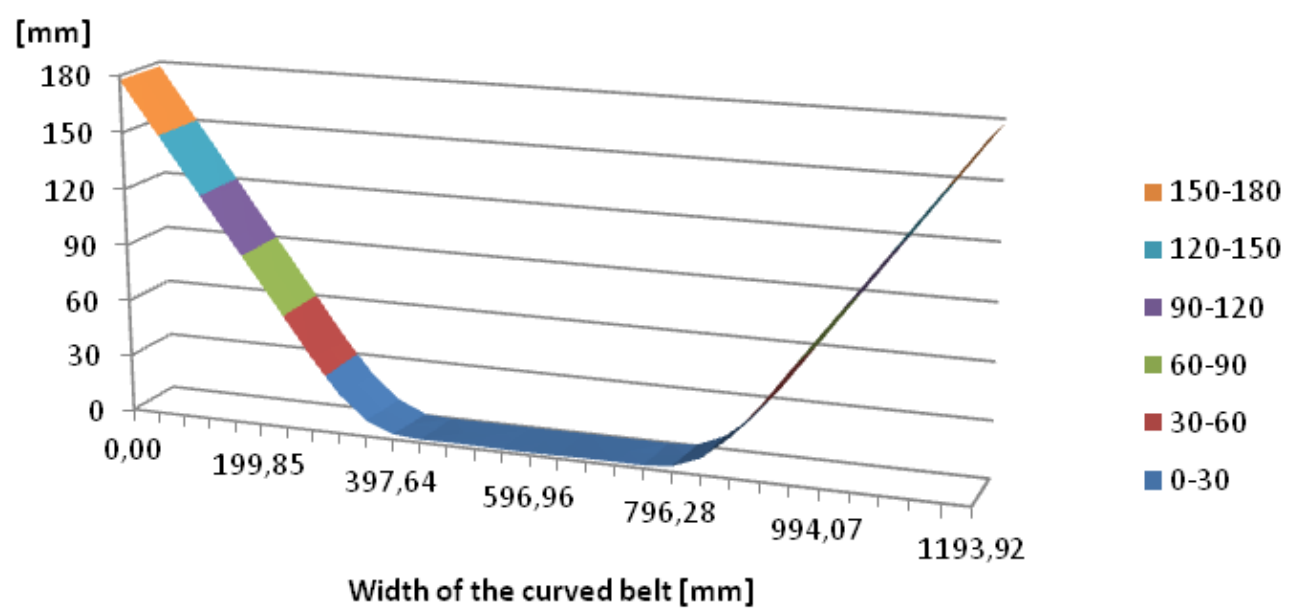

Fig. 22. Change of belt position above the third idler station (deformation of the belt above the idler station No. 3) 
CAE, used finite element methods. The input data for modeling, such as width or length of conveyor belts, the diameter of the drum, the diameter of rollers, or tensioning force, were chosen or calculated by solution of an example for calculation of belt conveyor. The model consisted of a conveyor belt with the length $4000 \mathrm{~mm}$ and width 1200 $\mathrm{mm}$, three idler stations with the length of the roller $450 \mathrm{~mm}$ and radius $70 \mathrm{~mm}$, and drum with the radius $500 \mathrm{~mm}$ and length $1400 \mathrm{~mm}$. Rollers and the drum were stepped at $1000 \mathrm{~mm}$ intervals. The belt was at the point of passage through the drum stretched by the tensioning force 10686,14 $\mathrm{N}$ or $0,05 \mathrm{MPa}$. The data that were obtained after the model ending, were analyzed in a form of graphs and then compared to each other. By comparison of individual parts, it was found, that the highest roller pressure measured on the idler station, created by rotation of rollers, has the value 28,2 MPa. Conversely, the lowest measured value on the idler station was equal to $0 \mathrm{MPa}$, because it was measured in the middle roller, and it was not rotated. By comparison of the results of deformation of the conveyor belt over idler stations, it was found that the measured values are almost identical, whereas the belt formed at all stages in the same way, because in any of the measured parts the properties of the conveyor belt did not change and also the angle of rollers rotation, which was $30^{\circ}$ in all cases. The model did not deliberate the frictional forces from the driving drum to the conveyor belt, and also it did not the deliberate operating speed of the driving drum because it was not necessary to model. However, if they were used, more realistic and accurate data and values about the conveyor belt, would be obtained.

\section{Acknowledgements}

This work is a part of these projects VEGA 1/0063/16, KEGA 014STU-4/2015, KEGA 018TUKE-4/2016.

\section{REFERENCES}

1. Mantič M., Kul'ka J., Krajňák J., Kopas M., Schneider M. Influence of selected digitization methods on final accuracy of 3D model. In: Majerník, M., Daneshjo, N., and Bosák, M. (eds.) Production Management and Engineering Sciences. pp. 475-480. CRC Press Taylor and Francis Group A Balkema Book, 2016.

2. Madáč K., Durkáč V., Král' J. Design of applications for CAD system Creo Parametric 1.0. Int. Sci. Her., 4, 2012, 278-284.
3. Strohmandl J. Use of simulation to reduction of faulty products. UPB Sci. Bull. Ser. D Mech. Eng., 76, 2014, 223-230.

4. Bukoveczky J., Gulan, L., Schmidtova, C. One method of mass classes creation demonstrated on excavators. In: Transport means 2014 : proceedings of the 18th international conference. pp. 397400, 2014.

5. Honus, S., Bocko, P., Bouda, T., Ristović, I., Vulić, M.: The effect of the number of conveyor belt carrying idlers on the failure of an impact place: A failure analysis. Eng. Fail. Anal., 77, 2017, 93-101.

6. Debski H., Koszalka G., Ferdynus M. Application of FEM in the analysis of the structure of a trailer supporting frame with various operation parameters. Eksploatacja i Niezawodnosc - Maintenance and Reliability, 14, 2012, 107-113.

7. Molnár, V., Fedorko, G., Stehlíková, B., Tomašková, M., Hulínová, Z., Analysis of asymmetrical effect of tension forces in conveyor belt on the idler roll contact forces in the idler housing, Meas. J. Int. Meas. Confed. 52 (2014) 22-32. doi:10.1016/j.measurement.2014.02.035.

8. Molnár, V., Fedorko, G., Stehlíková, B., Michalik, P., Weiszer, M., A regression model for prediction of pipe conveyor belt contact forces on idler rolls, Meas. J. Int. Meas. Confed. 46 (2013) 3910-3917. doi:10.1016/j.measurement.2013.07.045.

9. Molnár, V., Fedorko, G., Stehlíková, B., Michalik, P., Kopas, M., Mathematical models for indirect measurement of contact forces in hexagonal idler housing of pipe conveyor, Meas. J. Int. Meas. Confed. 47 (2014) 794-803. doi:10.1016/j.measurement.2013.10.012.

10. Rozbroj J., Zegzulka J., Nečas J. Use of DEM in the Determination of Friction Parameters on a Physical Comparative Model of a Vertical Screw Conveyor. Chem. Biochem. Eng. Q., 29, 2015, 25-34.

11. Neradilová, H., Laskovsky, V., The use of ecological systems for transporting of raw materials in the Czech Republic. In: 16th International Multidisciplinary Scientific GeoConference SGEM 2016. pp. 943-950, 2016.

12. Zienkiewicz, O.C.; Taylor, R.L.; Zhu, J.Z. (2005). The Finite Element Method: Its Basis and Fundamentals (Sixth ed.). Butterworth-Heinemann. ISBN 0750663200

13. Gajdos I., Slota J., Spisak E., Jachowicz T. and TorSwiatek A. Structure and tensile properties evaluation of samples produced by Fused Deposition Modeling. Open Eng., 6, 2016, 86-89.

14. ABAQUS/Explicit,Version 6.9-1. Simulia documentation for the Abaqus Unified FEA product suite. T. , Providence, 2009. 
15. Lodewijks G. On the application of beam elements in Finite Element models of belt conveyors. Part II. Bulk Solids Handling, 15 (1995), pp. 571-591

16. Lodewijks G. On the application of beam elements in Finite Element models of belt conveyors. Part I. Bulk Solids Handling, 14 (1994), pp. 729-737

17. Lodewijks G. On the application of beam elements in Finite Element models of belt conveyors. Part II. Bulk Solids Handling, 15 (1995), pp. 571-591

18. Mazurkiewicz M. Problems of identification of strength properties of rubber materials for purposes of numerical analysis: a review. Arch Civil Mech Eng, X (2010), pp. 1-16

19. Bukoveczky J., Gulan, L., Schmidtova, C. One method of mass classes creation demonstrated on excavators. In: Transport means 2014 : proceedings of the 18th international conference. pp. 397400, 2014.

20. Palenčár R., Ďuriš, S., Dovica, M., Palenčár, J. Application of Monte Carlo method for evaluation of uncertainties of temperature measurement by SPRT. In: IMEKO 21 World Congress. pp. 1-6, 2015. 